\title{
Potential for endozoochorous seed dispersal by sheep and goats: Risk of weed seed transport via animal faeces
}

\author{
Mostafa Oveisi $^{1}$ iD | Ahmad Ojaghi ${ }^{1}$ | Hamid Rahimian Mashhadi ${ }^{1}$ | \\ Heinz Müller-Schärer ${ }^{2}$ | Kamran Reza Yazdi ${ }^{3}$ | Behnaz Pourmorad Kaleibar ${ }^{1}$ | \\ Elias Soltani ${ }^{4}$
}

\author{
${ }^{1}$ Department of Agronomy and Plant \\ Breeding, University of Tehran, Karaj, Iran \\ ${ }^{2}$ Department of Biology, University of \\ Fribourg, Fribourg, Switzerland \\ ${ }^{3}$ Department of Animal Science, University \\ of Tehran, Karaj, Iran \\ ${ }^{4}$ Department of Agronomy and Plant \\ Breeding Sciences, College of Aburaihan, \\ University of Tehran, Pakdasht, Iran

\section{Correspondence \\ Mostafa Oveisi, Department of Agronomy and Plant Breeding, University of Tehran, \\ Email: moveisi@ut.ac.ir} \\ Karaj, Iran.
}

Subject Editor: Diego Batlla

Universidad de Buenos Aires, Buenos Aires, Argentina

\begin{abstract}
Endozoochory is known as an important mechanism for the spread of weeds. We carried out experiments to assess the fate of seeds of several weed species (Convolvulus arvensis, Cuscuta campestris, Rumex crispus, Hordeum spontaneum and Sorghum halepense) after passing through the gut of sheep and goat. Eighteen animals of both sheep and goat received diet mixed with seeds of the weed species or control with only wheat bran (five weed species + control $\times$ three replications). Results showed that a higher proportion of seeds were missing after passage through the sheep gut than in goats. In goats, a greater proportion of seeds were dead after passage, but the number of seeds collected from dung was also greater. Weed species differed, with the highest seed recovery and viability in Cuscuta campestris. Based on time of seed passages through the animal gut estimated for the different weed species, we recommend that sheep should be kept in a corral for $96 \mathrm{hr}$ to minimise seed transportation via their faeces. For goats, if $R$. crispus and C. arvensis seeds could be excluded from the diet, then maintaining them for $96 \mathrm{hr}$ in an animal stall would ensure little seed transportation via dung, but we found $R$. crispus and $C$. arvensis seeds to be present and viable in goat dung even $120 \mathrm{hr}$ after feeding. Very large numbers of viable seeds can be found in goat and sheep dung, so the use of rotted manure is highly recommended to avoid transportation of viable seeds via manure fertilisers.

K E Y WOR D S

gut passage, seed recovery, seed transmission, seed viability, weed species
\end{abstract}

\section{1 | INTRODUCTION}

Seed dispersal plays a crucial role in the 'success' of many weed species. An important effective way of seed dispersal is by animals through both ectozoochorous and endozoochorous modes (Wang et al., 2017). In regions with regular livestock movement, for example in central Asia, zoochory is probably one of the most important mechanisms of seed dispersal (Bläß et al., 2010). Seed dispersal by animals is not only important in rangelands and natural ecosystems, but also in non-grazed ones. Weed seeds can be transported after ingestion by animals and shed directly in pastures or spread via fresh manure to arable fields (Petit et al., 2013). Manures from sheep, goats, cows and pigs are used as fertilising materials in organic agricultural fields (Issaka et al., 2012). In sampling of 12 milking-cow and heifer barns on six New York farms, 133 thousand weed seeds per $\mathrm{kg}$ fresh manure were observed (Pleasant \& Schlather, 1994). Sheep can disperse 40 thousand seeds per animal every year (Welch, 1985). Thirty-seven per cent of the local plant species were found as viable seeds in sheep dung (Pakeman, 2001). Seeds of weed species infesting forage production farms are reported to be frequent in daily diet of livestock (Shaheen et al., 2014). 
After passage through the animal gut, some seeds are killed, while others may become less dormant and hence more germinable (Baskin \& Baskin, 2014). Seed germination response to animal gut can be highly species-specific. In cattle, the estimated time to $50 \%$ viability loss after seed intake ranged from $65 \mathrm{hr}$ for Rumex crispus L. (curly duck) to $76 \mathrm{hr}$ for Polygonum aviculare L. (common knotweed) (Rahimi et al., 2016). In a study by Wang et al. (2017), percentage seed recovery ranged between $12.6 \%$ and $17.6 \%$ for leguminous species and between $0.8 \%$ and $3.2 \%$ for gramineous species.

There are great differences among animal species, but also among individuals of the same species, in seed fate through their guts (Cirujeda et al., 2019). One animal may have numerous viable seeds in the pellets, while, another has none (Heady, 1954). Rahimi et al. (2016) showed different cattle types were different in seed recovery and viability.

The size of animal is important in seed dispersal. It was found that larger primates (i.e. those with longer digestive tracts) may be more effective seed dispersers as seeds germinated earlier and seedlings performed better the longer the time they spent in the acid (i.e. stimulated gut; Chac, 2014). Retention time is also positively correlated with animal size; therefore, it is lowest in rabbit gut which is $31 \mathrm{hr}$ while in cattle, sheep and horse it is 71,41 and $66 \mathrm{hr}$, respectively (Illius \& Gordon, 1992). For goat, the passage time of seeds through the gut ranged from 12 to $96 \mathrm{hr}$ depending on the weed species (Harrington et al., 2011; Wang et al., 2017).

Apart from strong effect of animals and weed species, the interactions between weed species and animals are also important (Bilal, 2015). Fazelian et al. (2014) tested the seed germination of 39 plant species excreted from faeces of cattle, sheep and goat, showing that while seed traits highly determined their fate through animal guts, this could be very interactive with physical and chemical properties of animal digestive tracts.

Convolvulus arvensis L. (field bindweed) (Orloff et al., 2018), Cuscuta campestris Yuncker (dodder) (Saric-Krsmanovic et al., 2018), R. crispus (Iqbal et al., 2019), Sorghum halepense L. Pers. (johnson grass) (Peerzada et al., 2017) and Hordeum spontaneum L. (wild barley) (Hosseini et al., 2019) are common grassland weeds and they vary in seed characteristics, such as size, shape and hardness (Hogan
\& Phillips, 2011). As their seeds remain viable in dairy manure (Demirhan and Ozyazici, 2019; Liu et al., 2020; Rahimi et al., 2016), restrictions are often imposed when using organic fertiliser containing weed seeds (Mt \& Schlather, 1994).

Worldwide, stock numbers have increased in the last 20 years from 1 billion to 1.1 billion for sheep and from 0.4 billion to 0.5 billion for goats (Terrili, http://www.fao.org/3/ah221e/AH221E01. $\mathrm{htm}$ ). These two species are commonly grazed and raised in the same flocks (Yakhchali \& Ranjbargarmabolia, 2008). Because of their different body mass and gut traits, they also differ in their potential for endozoochory (Degen, 2007) and, therefore, must be treated differently to control movement of weed seeds through their grazing and in their fresh manure.

In this study, we ask four main questions: (a) how different do the seeds of the common weeds $C$. arvensis, $C$. campestris, $R$. crispus, $S$. helepense and $H$. spontaneum pass through the gut of sheep and goat? (b) what is the duration of the species-specific passage and excretion through the digestive tract? (c) for how long will the seeds of these weeds remain viable in the fresh manure of sheep and goats? (d) based on our results, what can be recommended with regard to the safe movement of sheep and goats to avoid transportation of viable and germinable seeds to new areas?

\section{2 | MATERIALS AND METHODS}

\section{1 | Seed collection}

Intact seeds of C. arvensis, C. campestris, S. halepense, H. spontaneum and dry fruits of $R$. crispus were collected from maize (Zea mays L.) and alfalfa (Medicago sativa L.) fields in Karaj, Iran $\left(35.8400^{\circ} \mathrm{N}, 50.9391^{\circ} \mathrm{E}\right)$ in October 2013 and 2015 . The collected seeds were air-dried, and waste materials and immature seeds were removed. Undamaged seeds were stored in paper bags at room temperature until start of the experiment (one month at the temperature of $20-23^{\circ} \mathrm{C}$ ). Three replicates of 1,000 seeds from each weed species were weighted to obtain 1,000-Seed weight. The length and width of seeds were also measured using Vernier calliper (Table 1).

TABLE 1 Seed characteristics of the weed species used in the experiment $\left({ }_{ \pm} S E\right)$

\begin{tabular}{|c|c|c|c|c|c|c|}
\hline \multirow[b]{2}{*}{ Weed species } & \multicolumn{3}{|l|}{2013} & \multicolumn{3}{|l|}{2015} \\
\hline & Length (mm) & Width (mm) & $\begin{array}{l}1,000 \text {-seed } \\
\text { weight }(\mathrm{g})\end{array}$ & Length (mm) & Width (mm) & $\begin{array}{l}1,000 \text {-seed } \\
\text { weight }(\mathrm{g})\end{array}$ \\
\hline Convovulus arvensis L. & $3.00(0.001)$ & $2.00(0.002)$ & $4.00(0.280)$ & $3.00(0.002)$ & $2.00(0.01)$ & $4.50(0.560)$ \\
\hline Cuscuta campestris Yuncker. & $1.50(0.02)$ & $1.50(0.001)$ & $0.76(0.110)$ & $1.80(0.01)$ & $1.80(0.02)$ & $0.81(0.002)$ \\
\hline $\begin{array}{l}\text { Hordeum spontaneum C. } \\
\text { Koch. }\end{array}$ & $13.20(0.03)$ & $0.60(0.01)$ & $46.40(1.360)$ & $12.10(0.003)$ & $0.45(0.002)$ & $42.00(1.050)$ \\
\hline Rumex crispus L. $^{a}$ & $2.50(0.002)$ & $2.00(0.001)$ & $2.00(0.280)$ & $2.50(0.002)$ & $1.90(0.002)$ & $1.50(0.043)$ \\
\hline Sorghum halepense L. & $4.00(0.001)$ & $1.50(0.001)$ & $4.61(0.050)$ & $4.50(0.001)$ & $2.00(0.01)$ & $5.10(0.310)$ \\
\hline
\end{tabular}

${ }^{\mathrm{a}}$ For Rumex crispus, the characteristics of fruits were measured. 


\section{2 | Experimental design}

A repeated measure experiment was conducted in a factorial arrangement of treatments with three replications. The experiment was repeated twice during 2013 and 2015. Experimental factors were animals, comprised of indigenous sheep (Ovis aries L.) and goats (Capra aegagrus hircus) and weed species as described above. Female sheep and goats with average body weight of, respectively, 44.5 $( \pm 0.39)$ and $36.9( \pm 0.31) \mathrm{kg}$ in 2013 and $45.0( \pm 0.25)$ and $38.5( \pm 0.44)$ $\mathrm{kg}$ in 2015 were chosen for the experiments. Eighteen sheep and 18 goats were placed individually in wooden boxes $(1.5 \mathrm{~m} \times 0.7 \mathrm{~m})$ with $1.25 \mathrm{~m}$ distance and fed with common diet (Table 2).

Animals were put inside the boxes $24 \mathrm{hr}$ before the experiment to allow them to acclimate to the experimental conditions. Daily amount of sheep and goat food was considered 3 and $1.5 \mathrm{~kg}$ (Lacey et al., 1992). Seeds of each weed species were added to the diet in a ratio of 1,500 seeds $\mathrm{kg}^{-1}$ diet. Hence, the diet fed to every sheep and goat on the first day only consisted of 4,500 and 2,250 seeds, respectively. Weed species seeds were mixed homogenously with $200 \mathrm{~g}$ wheat bran and then added to each animal's daily diet. Fresh water and salt blocks were also provided ad libitum.

Each animal received diet mixed with one of the weed species seeds or control diet with only wheat bran (seed-free diet) (five weed species + control $\times$ three replicates $=18$ animals). The diet was hourly monitored to make sure that all of seeds were eaten. Faeces collection commenced $24 \mathrm{hr}$ after feeding and was continued for 5 days. Daily faecal materials were carefully collected off the floor and the boxes became completely clean (Lacey et al., 1992). At each faeces collection, five subsamples were taken from each animal faeces using a cream scoop. Each subsample represented about $4 \%$ to $7 \%$ of the total daily output of an individual animal, as the bulk density of the dungs was not the same over time (Lacey et al., 1992). Faeces were washed with faucet water through a wire sieve (80 mesh) until the water was clear. Hard faeces were immersed in cold water until soft (Tjelele et al., 2012). A sifter (60 mesh) was used to separate seeds from faecal remains. Undamaged seeds derived from

TABLE 2 Ingredients of the diet of sheep and goats

\begin{tabular}{|c|c|c|}
\hline \multirow[b]{2}{*}{ Diet materials } & \multicolumn{2}{|c|}{ Diet amount (g) } \\
\hline & Sheep & Goat \\
\hline Wheat straw & 470 & 240 \\
\hline Alfalfa & 360 & 190 \\
\hline Barley & 450 & 215 \\
\hline Beet pulp & 110 & 50 \\
\hline Wheat bran ${ }^{a}$ & 120 & 62 \\
\hline Mineral and vitamin & 20 & 11 \\
\hline Salt & 10 & 6 \\
\hline Corn silage & 1,500 & 780 \\
\hline Total & 3,040 & 1,554 \\
\hline
\end{tabular}

${ }^{a}$ In addition to these amounts, $200 \mathrm{~g}$ wheat bran was mixed with the seeds before adding seeds to the daily diet of each animal. daily faeces were counted to determine seed recovery for each day. Seeds were then stored in plastic bags in a cool dry place for further testing (Tjelele et al., 2012). On average, more than 60 seeds were recovered per sample for sheep and more than 38 seeds for goats. In order to standardise the tests, we used 30 seeds for each germination test that were placed in a Petri dish.

\section{3 | Viability and germination testing}

Seeds before feeding to animals and after recovery from each animal were subjected to germination and viability tests. Germination test was conducted in a germination chamber. Seeds of $C$. arvensis and S. halepense were maintained at $30^{\circ} \mathrm{C}$ in darkness; C. campestris seeds were maintained at the same temperature, but exposed to $8 \mathrm{hr}$ daily light (Benvenuti et al., 2005) and $H$. spontaneum and $R$. crispus seeds were exposed to $25^{\circ} \mathrm{C}$ and darkness for germination testing (Taylorson \& Hendricks, 1972). From each replicate, 30 seeds of each weed species were put in $8 \mathrm{~cm}$ glass dishes that had one disc of germination paper and $10 \mathrm{ml}$ of distilled water. Germination was counted daily based on radicle protrusion $(2 \mathrm{~mm}$ ) for 14 days. The tetrazolium test was used to determine viable seeds. For this, nongerminated seeds were first pricked or scratched to break any hard seed coats and then sectioned to expose the embryo and stained with 2,3,5-triphenyl tetrazolium chloride solution in distilled water with $\mathrm{pH} 7$ at $20^{\circ} \mathrm{C}$ in darkness. After $48 \mathrm{hr}$, seeds whose embryos had stained red and had firm flesh were classified as viable. Nongerminated seeds with complete embryo colouring were thus considered to be dormant seeds. At any time after feeding (TAF), the total number of viable seeds comprised the number of recovered seeds that germinated and the number that were determined as dormant.

\section{4 | Statistical analyses}

A combined analysis was performed to data; as the effect of year was significant, therefore the data of each experiment (year) were analysed and shown separately. The effects of animal type, weed species and TAF on recovery, viability and germinability of ingested seeds were subjected to mixed effects analysis that was performed in R-studio using package nlme (Pinheiro et al., 2020). Percentage data were arcsine transformed before analysis to meet the normality assumption for the analysis of variance (Zar, 2014). For statistical comparisons, we used protected least significant difference (LSD). The interactions were analysed and presented using non-linear regression. SigmaPlot (12.5) was used for non-linear regression analysis. Seed recovery (\%) in sheep and viability (\%) in both sheep and goat over TAF were described using a logistic model as follows:

$$
y=\frac{a}{1+\left(\frac{\mathrm{TAF}}{T_{50}}\right)^{b}}
$$


where $y$ represents seed recovery or viability (\%), $a$ is the maximum seed recovery or viability (\%) that occurs with initial extraction time, $T_{50}$ denotes the time for $50 \%$ reduction in $a$, and $b$ is the slope at the linear part of the curve (rate of seed recovery or viability decrease over TAF).

The percentage of germination over TAF for both sheep and goat and recovery for goat were described with a Gaussian model as follows:

$$
y=y_{0}+c * \exp \left(-0.5\left(\frac{\mathrm{TAF}-x_{0}}{d}\right)^{2}\right)
$$

where $y$ is seed recovery or germination (\%), $c$ is the maximum seed recovery or germination (\%), $x_{0}$ is the time at which the $c$ value occurs, $y_{0}$ is seed germination or recovery at first assessment ( $24 \mathrm{hr}$ after feeding) and $d$ is the standard deviation of $y$.

Model fit was assessed using the lack of fit test, root mean square of error (RMSE), adjusted $R$-squared $\left(R_{\mathrm{adj}}^{2}\right)$ and the standard error of parameters.

\section{3 | RESULTS}

The seed viability and germination of each weed species at the beginning of the experiment are shown in Table 3. Seeds of H. spontaneum were completely lost through the digestive tract of both sheep and goats and no seeds were recovered from the faeces samples over TAF. For the remaining weed species, mixed effect analysis indicated significant interactions between animal type, weed species and time (TAF) on seed recovery, viability and germination percentage $(p \leq 0.05)$. Therefore, interactions were further described using non-linear regression.

\section{1 | Comparison between sheep and goat}

Figure 1 shows an overall comparison of recovery, viability and germinability of weed seeds in sheep and goat dung after $120 \mathrm{hr}$. Averaged over both years, a significantly higher number of seeds were missed in sheep than goat guts (Figure 1). However, per cent of dead and dormant seeds were higher in goat dung. Also, seeds extracted from goat faeces were more germinable than those obtained from sheep dung. The per cent dead, viable and germinable seeds differed between weed species, as in sheep, a higher per cent of the recovered seeds of $C$. campestris and $R$. crispus were dormant, while for other weed species the ratios were approximately the same. In goat, a high per cent of $C$. campestris seeds were dormant.

Averaged over years and weed species, sheep dung contained $19 \%$ of the fed seeds, of which $4.25 \%$ (standard error $=1.32$ ) were dead, $11 \%$ (4.3) were dormant and $3.62 \%$ (1.38) were germinable. Goat dung contained $33 \%$ of the fed seeds of which $14 \%$ (6.35) were dead, $22 \%$ (5.19) were dormant and 7\% (2.3) were germinable. Therefore, a significantly higher number of seeds were recovered from goat dung ( $p<0.05)$, with a higher percentage of dead, dormant and germinable seeds ( $p<0.05$, with LSD values for dead, dormant and germinable seeds of 4.2, 4.5 and 1.4, respectively).

Averaged over all weed species, seed recovery was significantly lower in 2013 than in $2015(p<0.01$, LSD $=4.7)$, with the recovery of $14.8 \%$ (2) and $23 \%$ (3.4) of seeds for sheep and $32.3 \%$ (3) and $54 \%$ (4.1) for goats in 2013 and 2015, respectively.

\section{2 | Seed fate through the sheep gut}

\subsubsection{Seed recovery over TAF}

For both years, C. campestris showed the highest seed recovery (Table 4). In general, seed recovery was higher at the beginning and decreased with TAF. For example, in C. campestris with increasing TAF from 24 to $120 \mathrm{hr}$, seed recovery decreased from $10 \%( \pm 2.0)$ to $0.67 \%( \pm 0.2)$ in 2013 , and from $16.50 \%( \pm 3.4)$ to $1 \%( \pm 0.1)$ in 2015 (Figure 2). The decreasing trend of seed recovery (\%) over TAF was described using Equation 1.

The seed recovery of $C$. arvensis was initially (TAF $=24 \mathrm{hr}$ ) higher than S. halepense and R. crispus (Table 4). In 2013, 48 hr after feeding, the three weed species had the same amount of seed recovery, while in 2015, C. arvensis showed higher seed recovery than S. halepense and $R$. crispus with TAF (Figure 2).

\begin{tabular}{|c|c|c|c|c|}
\hline \multirow[b]{2}{*}{ Weed species } & \multicolumn{2}{|l|}{2013} & \multicolumn{2}{|l|}{2015} \\
\hline & Viability (\%) & $\begin{array}{l}\text { Germination } \\
\text { (\%) }\end{array}$ & Viability (\%) & $\begin{array}{l}\text { Germination } \\
\text { (\%) }\end{array}$ \\
\hline Convovulus arvensis L. & $100.0(0.00)$ & $7.0(1.70)$ & $98.8(0.00)$ & $6.0(2.30)$ \\
\hline $\begin{array}{l}\text { Cuscuta campestris } \\
\text { Yuncker. }\end{array}$ & $98.6(0.01)$ & $13.0(2.00)$ & $99.8(0.01)$ & $10.0(3.50)$ \\
\hline $\begin{array}{l}\text { Hordeum spontaneum } \\
\text { C. Koch. }\end{array}$ & $100.0(0.00)$ & $19.0(5.30)$ & $100.0(0.00)$ & $17.0(4.30)$ \\
\hline Rumex crispus L. & $100.0(0.00)$ & $8.0(1.40)$ & $100.0(0.00)$ & $12.0(4.00)$ \\
\hline Sorghum halepense L. & $99.8(0.00)$ & $4.5(0.80)$ & $100.0(0.00)$ & $3.0(0.50)$ \\
\hline
\end{tabular}

TABLE 3 Initial weed seed viability and germination at the beginning of the experiments $( \pm S E)$ 
FIGURE 1 Proportion (\%) of seed absence, dead, dormant and germinable seeds in sheep and goat faeces after $120 \mathrm{hr}$. Different weed species for 2 years (2013 and 2015) are included. Bars show the standard error

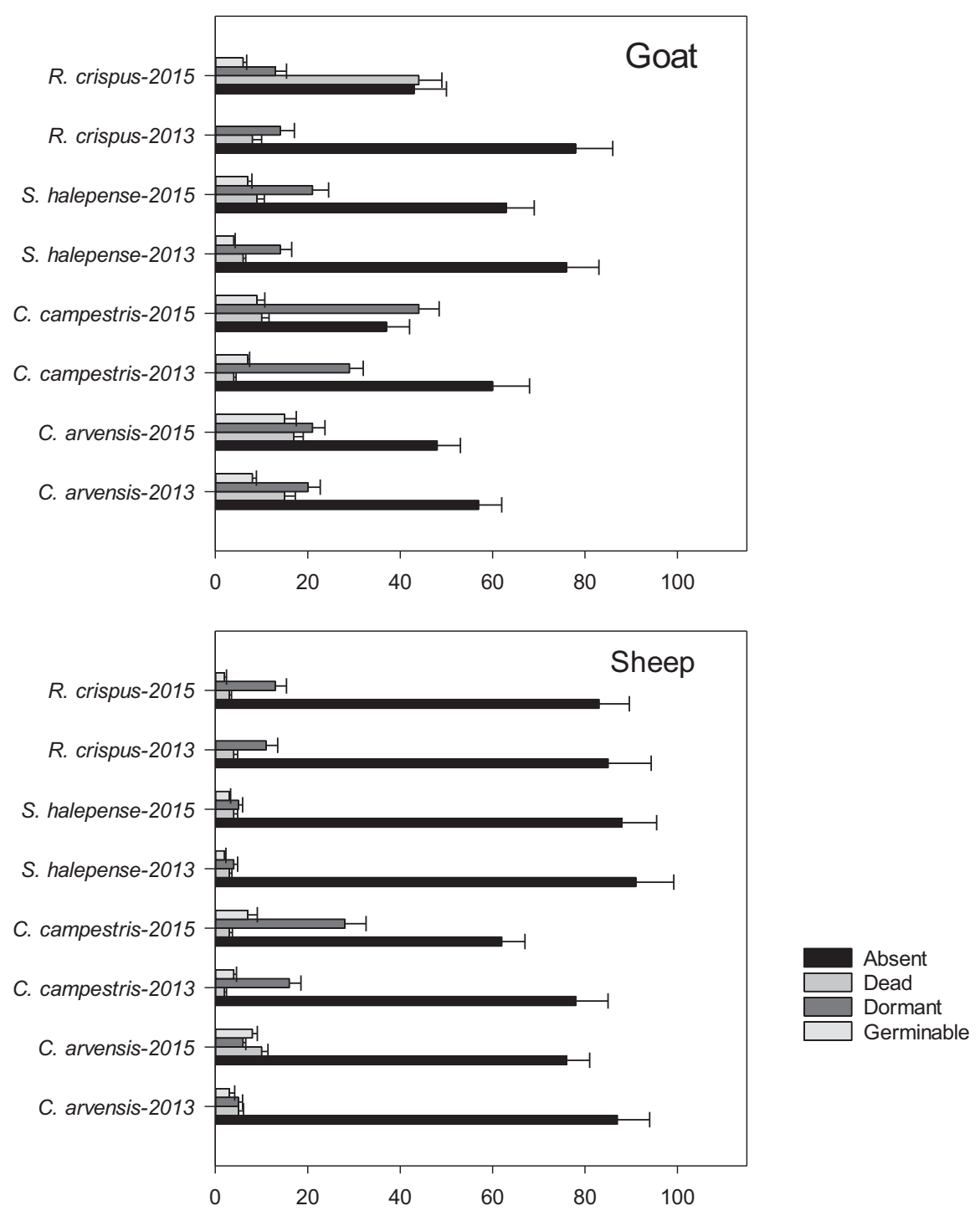

Proportion (\%) of seed absence, dead, dormant and germinble seeds of each species over 2013 and 2015

\subsection{2 | Seed viability over TAF}

Seeds viability over TAF was well described with logistic model equations (Equation 1). In both years, C. campestris seeds showed high levels of viability through the experiment. Viability of seeds collected $24 \mathrm{hr}$ after feeding was between $96( \pm 4.4)$ and $100 \%$, but decreased to $83 \%$ after $120 \mathrm{hr}$ (Figure 2). Rumex crispus seeds were also highly viable, while C. arvensis seeds showed on average the least viability of all weed species studied. Sorghum halepense seeds showed also a low viability, as in 2015 , the seeds extracted $120 \mathrm{hr}$ after feeding had viability less than $20 \%$.

\subsection{3 | Seed germination over TAF}

Germination (\%) over TAF significantly differed among weed species. Rumex crispus seeds showed no germination in 2013 and less than 7\% in 2015, with no visible trend over time. With $24 \mathrm{hr}$ after feeding, the highest germinable seeds belonged to $S$. halepense with $23 \%( \pm 3.6)$ and $16.5 \%( \pm 2.0)$ germination in 2013 and 2015, respectively; however, those severely decreased with TAF (Figure 2). Germination of $C$. arvensis and $C$. campestris seeds were low at the beginning and latest samplings, while showed a significant rise in middle time, therefore, a Gaussian model was used to describe changes in seed germination over TAF (Figure 2). However, the peak time was different between C. arvensis and C. campestris (parameter $x_{0}$ in Table 4). According to model estimates, for $C$. campestris, the faeces samples collected 85-90 hr TAF contained highest germinable seeds, while for $C$. arvensis the peak times were between 51 and $62 \mathrm{hr}$ after feeding (Table 4).

\section{3 | Seed fate through the goat gut}

\subsection{1 | Seed recovery over TAF}

Seed recovery from goat faeces showed different trends from sheep. As for all weed species, the seed recovery over TAF was peak type and well 


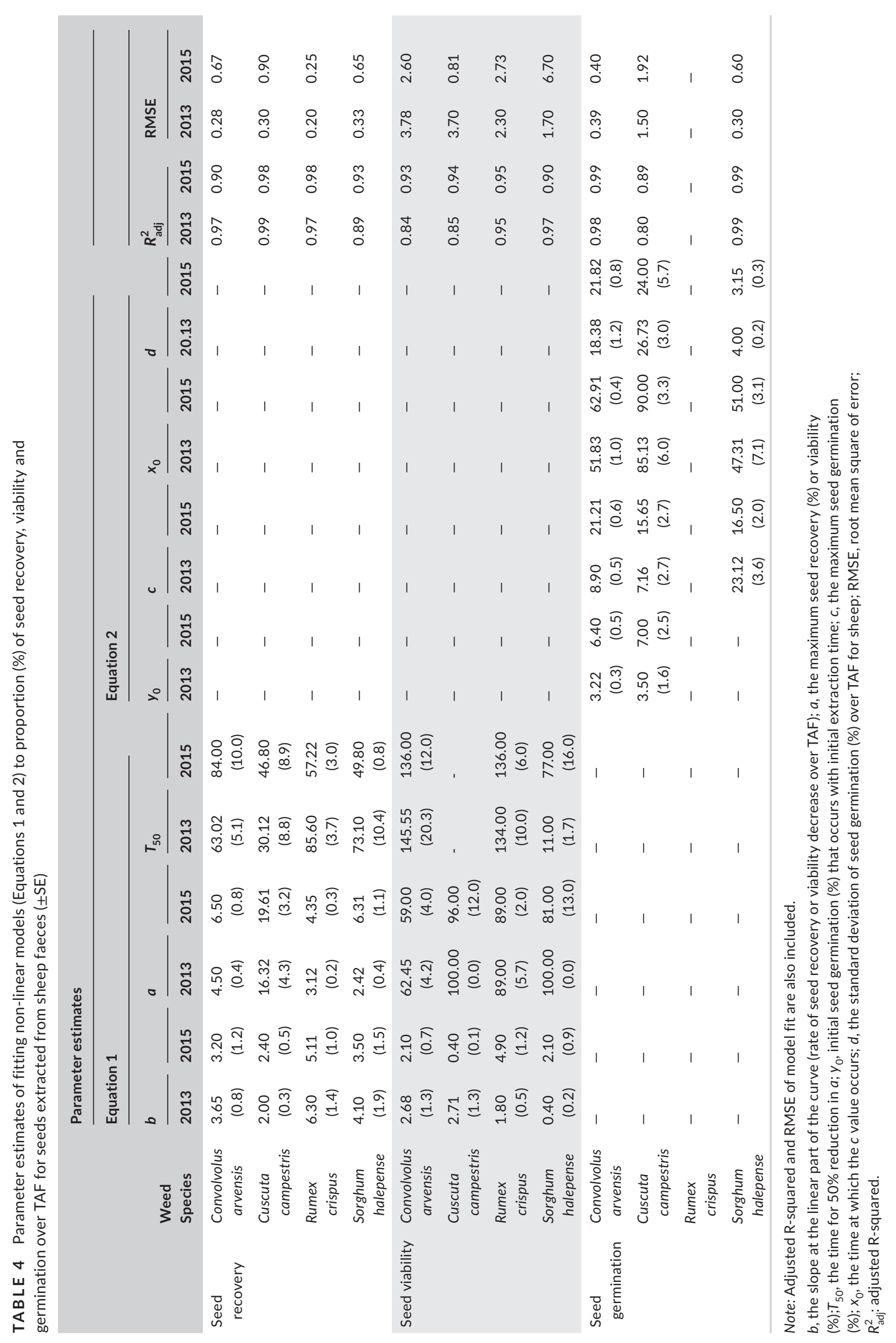


FIGURE 2 Change in seed recovery (\%), seed viability (\%) and seed germination (\%) with TAF for sheep and different weed species. The fitted lines are model predictions. Bars show the standard error of means

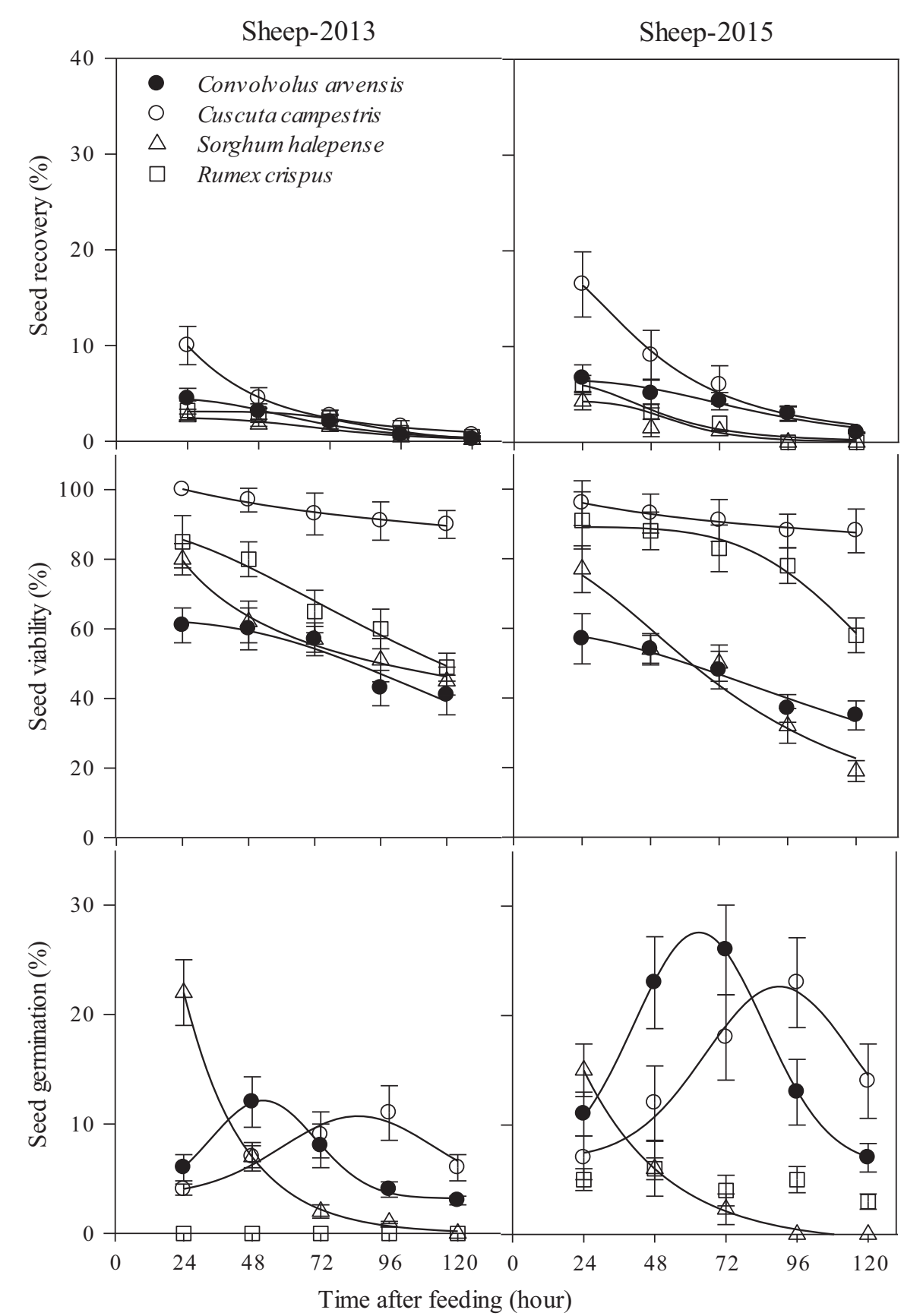

described by Gaussian model (Figure 3). Cuscuta campestris seeds were the most abundant seeds found in goat dung (Table 5). For both years, the peak seed recovery of $C$. arvensis, $C$. campestris, and $S$. halepense occurred between $40( \pm 1.4)$ and $49( \pm 0.6) \mathrm{h}$ after feeding. For R. crispus, the peak of seed recovery was estimated to occur $81( \pm 2.9) \mathrm{h}$ after feeding (Table 5).

\subsection{2 | Seed viability over TAF}

The viability of seeds found in goat dung decreased with TAF. The change in seed viability (\%) was well described using a logistic model (Equation 1; Figure 3), however, parameter estimates suggested significant difference between weed species. Cuscuta campestris showed highest viability (100\%) with early and middle TAF, however, with
$96 \mathrm{hr}$ after feeding decreased down to $70 \%( \pm 5.0)$ and $56 \%( \pm 3.6)$ in 2013 and 2015, respectively (Figure 3). Rumex crispus seeds also maintained their viability until $70 \mathrm{hr}$ after feeding then decreased. For S. halepense, maximum viability was $84 \%( \pm 0.6)$ observed in 2013 (Table 5). A rapid decline in the viability of $S$. halepense seeds occurred from 40 and $70 \mathrm{hr}$ after feeding, respectively for 2013 and 2015 (Table 5; Figure 3). Convolvulus arvensis seeds found $24 \mathrm{hr}$ after feeding had a viability of $60 \%$, suffering a $10 \%$ decrease over TAF.

\subsection{3 | Seed germination over TAF}

Germination of R. crispus seeds was lower than $2 \%$ and $7 \%$, respectively for 2013 and 2015. Germination of the other weeds followed 


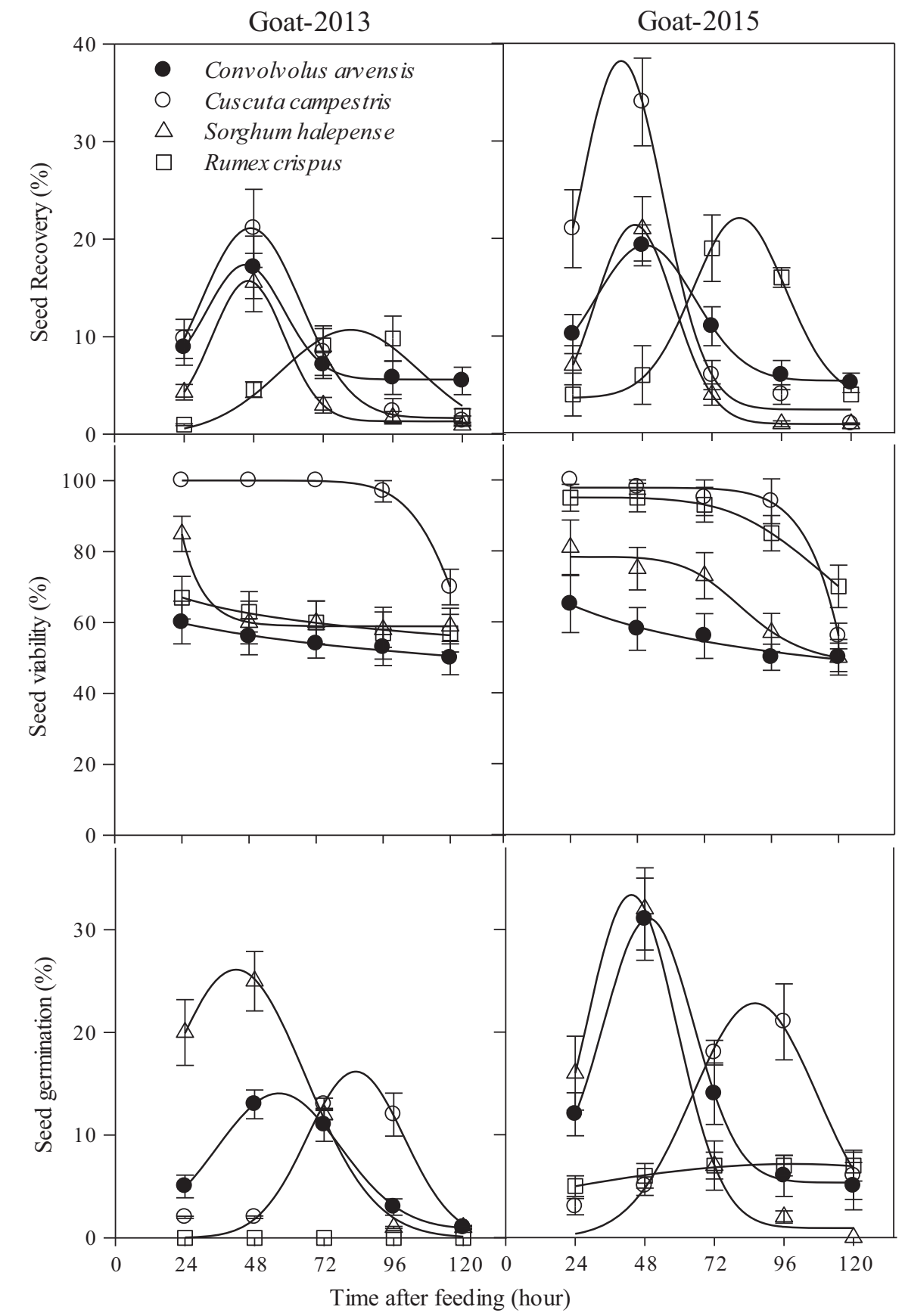

FIGURE 3 Change in seed recovery (\%), seed viability (\%) and seed germination (\%) with TAF for goat and different weed species. The fitted lines are model predictions. Bars show the standard error of means

a peak trend over TAF (Figure 3). Goat dung collected between 38 and $85 \mathrm{hr}$ after feeding contained the highest number of germinable seeds (Figure 3). Sorghum halepense seeds were the most frequent germinable seeds in goat dung and its peak time was estimated to be $38( \pm 0.6) \mathrm{hr}$ after feeding. The peak time for $C$. arvensis was estimated $82( \pm 1.8) \mathrm{hr}$ after feeding and occurred shortly after that for S. halepense with $56( \pm 0.3) \mathrm{hr}$ after feeding (Table 5).

\section{4 | DISCUSSION}

The fate of plant seeds following consumption by animals differs among weed species. Even congeneric plants often show little consistency in their response because of variations in seed morphology or age (Kuiters \& Huiskes, 2010). The current study shows the differential fate of seed recovery, viability and germination after passing through the animal gut. Seed recovery from digestive tracts depends on features such as size, shape, mass, hardness and age of ingested seeds (Gardener et al., 1993; Kuiters \& Huiskes, 2010; Wang et al., 2017).

Animal species also play an important role in seed dispersal by endozoochory. Sheep and goats are closely related and both belong to the subfamily Caprinae. However, there are differences in their anatomy, physiology and feeding behaviour. Sheep are grazing animals while goats are essentially browsing (Devendra, 1990). Grazers and browsers have measurable differences in the morphology of the 


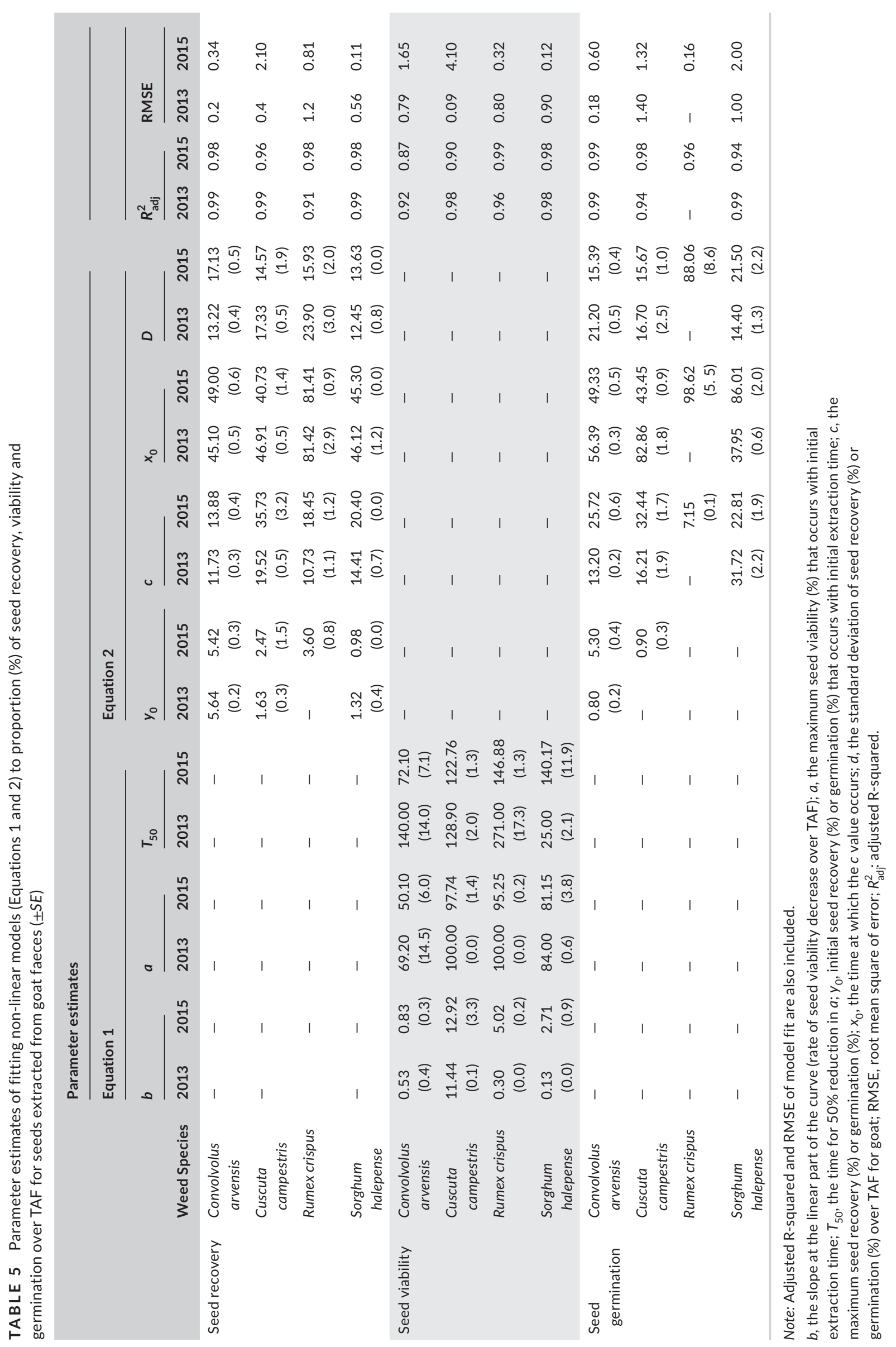


foregut (rumen, reticulum, abomasums, and omasum), the hindgut, salivary glands, mouth, teeth, liver, and body mass that may influence their ability to consume grasses and browses and its digestion (Odashima et al., 1991). Sheep have significantly longer rumen retention and mean retention times. In contrast, goats have faster passage rate through the digestive tract (Tsiplakou et al., 2011). Shipley (1999) also showed that the gut length of sheep is longer than that of goats. In line with this, we found that a larger proportion of seeds did not pass through the sheep gut, while more seeds were recovered from goat faeces. Goats have a higher fermentation rate in the rumen and also a higher absorption rate (Zoidis et al., 2018). This leads to more damage to seeds and thus, higher dead seeds were found in goat faeces. Moreover, the number of germinable seeds was higher in goat than sheep, but this could also be due to the chewing system in the goat that produces sever scarification to hard seed coats during the passage (Neto et al., 1987). The acids within the tract may have further promoted scarification of some of these hard seed coats (Harrington et al., 2011).

In sheep, the time of recovery was similar for seeds of the different weed species in both years. However, the magnitude of recovery (\%) was higher for C. campestris, which could be due to the size and shape of $C$. campestris seeds. The average size of the C. campestris seeds is about $1.5 \mathrm{~mm}$ (the smallest among the seeds studied) with spherical shape. According to Jensen et al. (1995), there might be an inverse relationship between seed size and recovery, as the small seeds are in general less digestible compared to the big seeds and more likely to escape mastication (Gökbulak, 2006). In line with this, we also found an overall trend of decrease of per cent seed recovery from animal dung with increasing seed weight (Figure 4). Seeds of $H$. spontaneum were completely lost through the digestive tract of both sheep and goat over TAF. This could be due to the larger seed size of this species compared to the other seeds. Larger seeds are more likely to get damaged than smaller seeds by chewing

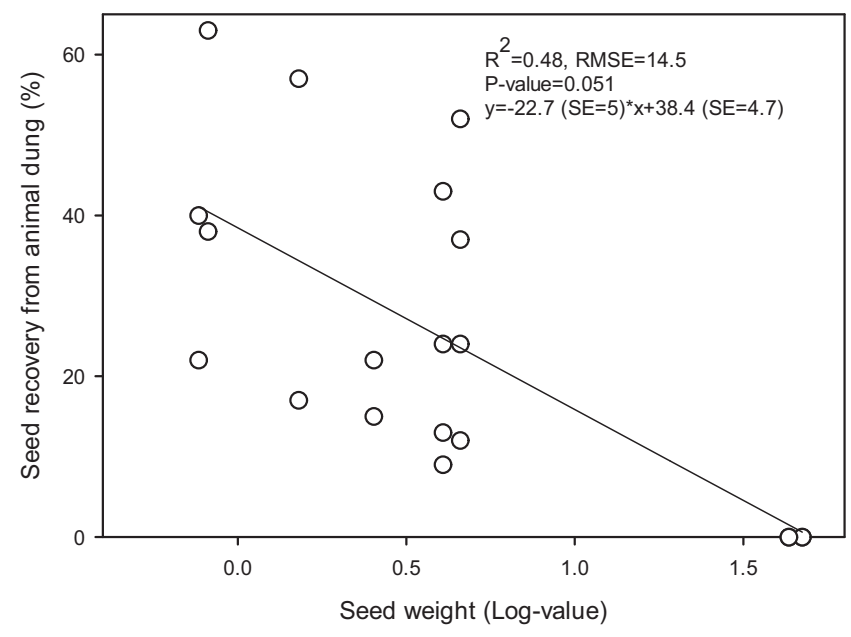

FIGURE 4 Relationship between overall per cent seed recovery from animal dung and seed weight (log-value) (pooled data of sheep and goats). R-square, RMSE value, $p$-value and line equation are shown during rumination. Harrington et al. (2011) found a negative linear relationship between seed size and the percentage of seeds recovered following passage through goats. In their trial, the two longest seeds had the lowest recovery. However, other studies showed that the percentage of recovery was positively correlated with seed size (Gardener et al., 1993; Wang et al., 2017) and that the shape was the main factor in seeds remaining undamaged. Furthermore, spherical seeds are reported to escape more easily from mastication and also pass the digestive tract more rapidly (Peco et al., 2006), while elongated seeds are more often lost through the animal gut. In line with this, we found that $H$. spontaneum, the species with the most elongated seeds among the weeds studied, was absent in animal dung and showing zero seed recovery, and the recovery was also low for S. halepense seeds that are relatively elongated. In contrast, seeds of $C$. campestris and $C$. arvensis are rounder and smaller and were more often recovered as viable seeds in animal dung (Table 1; Figure 1).

Traveset et al. (2008) suggested that in addition to seed size, the hardness of the seed coat is also an important factor in the success of seeds in passing through the digestive tract. Convolvulus arvensis seeds are of medium size (Traveset and Verdu, 2002), but classified as having a hard seed coat (Weaver \& Riley, 1982). Cuscuta campestris seeds also have a hard seed coat (Baskin \& Baskin, 2014) and a small size (Traveset and Verdu, 2002). The hard seed coat of these species may thus explain their higher recovery than the other weeds in sheep (Figure 1). In goats, C. campestris, C. arvensis and S. halepense were similar in recovery time, while the peak time for $R$. crispus seeds occurred with more delay (Figure 3). This could be because of the low specific gravity in $R$. crispus seeds (Rahimi et al., 2016). Gardener et al. (1993) found a negative correlation between retention time and specific gravity of seeds. They further reported that less dense seeds had the slowest passage and longest retention time through the digestive tract of cattle.

As shown, R. crispus seeds had a low seed recovery (Figures 2 and 3). The $R$. crispus seeds are not classified as hard seeds (Baskin $\&$ Baskin, 2014) and they are relatively large, so a large number of $R$. crispus seeds may be damaged or lost during passage through the digestive tract.

Seed dormancy of $C$. arvensis and C. campestris is classified as physical dormancy, while $R$. crispus and $S$. halepense are classified to have physiological dormancy (Baskin \& Baskin, 2014). We found Sorghum halepense seeds to be more germinable, but only in goat faeces. Chemical treatment with $\mathrm{H}_{2} \mathrm{SO}_{4}$ proved to be an effective method to break seed dormancy in S. halepense (Podrug et al., 2014), thus, germination of $S$. halepense seeds is expected to increase after passage through the animal gut.

Impermeable seed coats in C. campestris have two palisade layers and only the inner one is impermeable (Lyshede, 1992). This impermeable seed coat in C. campestris prevents germination. It has been shown that break of dormancy of $C$. campestris seeds can be reached after 20 min soaking in $\mathrm{H}_{2} \mathrm{SO}_{4}$ (Lados, 1998). Partial scarification in passing through the digestive tract could further breakdown seed dormancy of $C$. arvensis and $C$. campestris. To remove the innate dormancy of seeds of $R$. crispus, an initial period of low-temperature 
stratification is needed (Pye \& Andersson, 2009). Therefore, breaking the dormancy of $R$. crispus seeds is not expected to occur through the animal guts (Figure 3).

\section{5 | RECOMMENDATIONS TO AVOID TRASNPORTATION OF VIABLE AND GERMINABLE SEEDS TO NEW AREAS}

A higher per cent of seeds is missed through sheep than the goat gut. In goat, a larger number of seeds are recoverable from animal faeces; however, the number of dead seeds is also high. To compare weed species, the $C$. campestris seeds showed the highest seed recovery while no $H$. spontaneum seed was observed in animal dung. The recovered C. campestris seeds were mostly viable. In general, seeds viability decreased over TAF.

In sheep, seed recovery decreased in both years to less than 5\% after $72 \mathrm{hr}$, and especially for R. crispus and S. halepense, very few seeds were recovered after this time point. Viability of $C$. campestris seeds remained above $80 \%$ until $120 \mathrm{hr}$. The viability of the other weeds was also above $40 \%$ over $120 \mathrm{hr}$, except for S. halepense that fell to about $20 \%$ in the 2015 data. However, after 96 hr, very few seeds remained in sheep dung. Thus, we recommend that sheep should be kept in a corral for $96 \mathrm{hr}$ to minimise seed transportation via their faeces.

For goats, at least $50 \%$ of C. arvensis and R. crispus seeds were recovered during $120 \mathrm{hr}$ in 2015. In 2013, C. arvensis seeds showed about $50 \%$ recovery. In addition, at least $50 \%$ of seeds remained viable after $120 \mathrm{hr}$. If $R$. crispus and C. arvensis seeds could be excluded from the diet of goats, then maintaining them for $96 \mathrm{hr}$ in an animal stall would ensure little seed transportation via goat dung. However, we found R. crispus and C. arvensis seeds to be present and viable in goat dung even $120 \mathrm{hr}$ after feeding. The total number of viable seeds in animal faeces after $120 \mathrm{hr}$ (at which point more than $10 \%$ of seeds remained viable, often a much higher percentage) can be enormous if large numbers of seeds are fed to goat or sheep, especially for some weed species such as $C$. campestris that were still largely viable. Therefore, using rotted manure is highly recommended to avoid transportation of viable seeds in dung via manure fertilisers.

\section{ACKNOWLEDGEMENTS}

We wish to thank the Fadak Agro Industry Company for the financial support during the fieldwork.

\section{PEER REVIEW}

The peer review history for this article is available at https://publo ns.com/publon/10.1111/wre.12461.

\section{ORCID}

Mostafa Oveisi (iD https://orcid.org/0000-0003-0742-5485

Elias Soltani (iD https://orcid.org/0000-0003-0017-6703

\section{REFERENCES}

Baskin, C. C., \& Baskin, J. M. (2014) Seeds: ecology, biogeography, and evolution of dormancy and germination, 2nd ed. San Diego: Elsevier/ Academic Press.

Benvenuti, S., Dinelli, G., Bonetti, A., \& Catizone, P. (2005) Germination ecology, emergence and host detection in Cuscuta campestris. Weed Research, 45, 270-278.

Bilal, M. A. (2015) A review of endozoochorous seed dispersal by herbivores and its potential effect on seed germination. Master thesis, Norwegian University of Life Sciences, Ås, Norway.

Bläß, C., Ronnenberg, K., Tackenberg, O., Hensen, I., \& Wesche, K. (2010) The relative importance of different seed dispersal modes in dry Mongolian rangelands. Journal of Arid Environments, 74, 991-997.

Chac, D. (2014) Is there variation in the effects of primate size as seed dispersers?: Seed and seedling performance after gut simulation treatments in hydrochloric acid. University of Tennessee, Knoxville Trace: Tennessee Research and Creative Exchange.

Cirujeda, A., Pardo, G., Marí, A. I., Joy, M., \& Casasús, I. (2019) Emergence and viability of teosinte seeds (Zea mays ssp. mexicana ad int.) subjected to sheep digestion. Weed Research, 59, 145-154.

Degen, A. A. (2007) Sheep and goat milk in pastoral societies. Small Ruminant Research, 68, 7-19.

Demirhan, E., \& Ozyazici, M. A. (2019) Determination of vegetation and soil properties of the floodplain rangeland in the continental climate zone of turkey. Applied Ecology and Environmental Research, 17, 15531-15546.

Devendra, C. (1990). Comparative aspects of digestive physiology and nutrition in goats and sheep. In C. Devendra \& E. Imazumi (Eds.), Proceedings 1990 Ruminant nutrition and physiology in Asia (August 28, Japan society of zootechnical science. Sendai, Japan), pp. 45-60. Japan Society of Zootechnical Science, Sendai, Japan.

Fazelian, S., Tahmasebi, P., \& Shirmardi, H. A. (2014) Endozoochorous seed dispersal of plant species in semi-steppe rangelands. International Journal of Advanced Biological and Biomedical Research, 2, 473 -486 .

Gardener, C. J., Mclvor, J. G., \& Jansen, A. (1993) Passage of legume and grass seed through the digestive tract of cattle and their survival in faeces. Journal of Applied Ecology, 30, 63-74.

Gökbulak, F. (2006) Recovery and germination of grass seeds ingested by cattle. Journal of Biological Sciences, 6, 23-27.

Harrington, K. C., Beskow, W. B., \& Hodgson, J. (2011) Recovery and viability of seeds ingested by goats. New Zealand Plant Protection, 64, 75-80.

Heady, H. F. (1954) Viable seed recovered from fecal pellets of sheep and deer. Journal of Range Management, 7, 259-261.

Hogan, J. P., \& Phillips, C. J. C. (2011) Transmission of weed seed by livestock: a review. Animal Production Science, 51, 391-398.

Hosseini, M., Ghorbani, R., Mohassel, M. H. R., \& Yassaie, M. (2019) Correlation of environmental factors and phenotypic diversity of iranian wild barley (Hordeum Spontaneum Koch) populations. Acta Oecologica, 95, 19-25.

Illius, A. W., \& Gordon, I. J. (1992) Modeling the nutritional ecology of ungulate herbivores. Evolution of body size and competitive interactions. Oecologia, 89, 428-434.

Iqbal, M. F., Shad, G. M., Feng, Y. L., Liu, M. C., Wang, S., Lu, X. R. et al. (2019) Efficacy of postemergence herbicides for controlling curled dock (Rumex crispus I.) in wheat crops. Applied Ecology and Environmental Research, 17, 12753-12767.

Issaka, R. N., Buri, M. M., Tobita, S., Nakamura, S., \& Owusu-Adjei, E. (2012). Indigenous fertilizing materials to enhance soil productivity in Ghana. Soil Fertility Improvement and Integrated Nutrient Management-A Global Perspective, Whalen, KJ, pp. 119-134.

Jensen, S. K., Liu, Y. G., \& Eggum, B. O. (1995) The influence of variations in seed size and hull content on composition and digestibility 
of rapeseed. In Proceedings 1995 9th International Rapeseed Congress (4-7 July, Cambridge, UK). pp. 188-190.

Kuiters, A. T., \& Huiskes, H. P. J. (2010) Potential of endozoochorous seed dispersal by sheep in calcareous grasslands: correlations with seed traits. Applied Vegetation Science, 13, 163-172.

Lacey, J. R., Wallander, R., \& Olson-Rutz, K. (1992) Recovery, germinability, and viability of leafy spurge (Euphorbia esula) seeds ingested by sheep and goats. Weed Technology, 6, 599-602.

Lados, M. (1998) Effect of temperature, $\mathrm{pH}$ and host plant extracts on the germination of Cuscuta trifolii and C. campestris. Acta Agronomy Hung, 46, 317-325.

Liu, T., Wang, M., Awasthi, M. K., Chen, H., Awasthi, S. K., Duan, Y., \& Zhang, Z. (2020) Measurement of cow manure compost toxicity and maturity based on weed seed germination. Journal of Cleaner Production, 245, 118894.

Lyshede, O. B. (1992) Studies on mature seeds of Cuscuta pedicellata and C. campestris by electron microscopy. Annals of Botany, 69, 365-371.

Mt, J., \& Schlather, K. J. (1994) Incidence of weed seed in cow (Bos sp.) manure and its importance as a weed source for cropland. Weed Technology, 8, 304-310.

Neto, M. S., Jones, R. M., \& Ratcliff, D. (1987) Recovery of pasture seed ingested by ruminants. 1 . Seed of six tropical pasture species fed to cattle, sheep and goats. Australian Journal of Experimental Agriculture, 27, 239-246.

Odashima, M., Nam, K. T., Lee, S. L., Chiga, H., Kato, K., Otha, M., et al. (1991) Seasonal changes in particulate passage rate in gastro-intestinal tract and digestibility of Sika deer and sheep under restricted feeding conditions. Animal Science and Technology, 62, 308-313.

Orloff, N., Mangold, J., Miller, Z., \& Menalled, F. (2018) A meta-analysis of field bindweed (Convolvulus arvensis L.) and Canada thistle (Cirsium arvense L.) management in organic agricultural systems. Agriculture, Ecosystems and Environment, 254, 264-272.

Pakeman, R. J. (2001) Plant migration rates and seed dispersal mechanisms. Journal of Biogeography, 28, 795-800.

Peco, B., Lopez-Merino, L., \& Alvir, M. (2006) Survival and germination of Mediterranean grassland species after simulated sheep ingestion: ecological correlates with seed traits. Acta Oecologica, 30, 269-275.

Peerzada, A. M., Ali, H. H., Hanif, Z., Bajwa, A. A., Kebaso, L., Frimpong, D., et al. (2017) Eco-biology, impact, and management of Sorghum halepense (L.) Pers. Biological Invasions, 19, 1-19.

Petit, S., Alignier, A., Colbach, N., Joannon, A., Le Cœur, D., \& Thenail, C. (2013) Weed dispersal by farming at various spatial scales. A review. Agronomy for Sustainable Development, 33, 205-217.

Pinheiro, J., Bates, D., DebRoy, S., Sarkar, D., \& R Core Team. (2020). nlme: Linear and Nonlinear Mixed Effects Models. R package version 3.1147. https://CRAN.

Pleasant, J. M., \& Schlather, K. J. (1994) Incidence of weed seed in cow (Bos sp.) manure and its importance as a weed source for cropland. Weed Technology, 8, 304-310.

Podrug, A., Gadžo, D., Grahić, J., Srebrović, E., \& Đikić, M. (2014) Dormancy and germination of johnsongrass seed (Sorghum halepense (L.) Pers.). Herbologia, 14, 1-10.

Zoidis, E., Poulopoulou, I., Tsoufi, V., Massouras, T. \& Hadjigeorgiou, I. (2018) Effects of terpenes administration in the physiochemical characteristics of goat milk. International Journal of Dairy Technology, 71, 72-81.
Pye, A., \& Andersson, L. (2009) Time of emergence of Rumex crispus L. as affected by dispersal time, soil cover, and mechanical disturbance. Acta Agriculturae Scandinavica Section B-Soil and Plant Science, 59, 500-505.

Rahimi, S., Mashhadi, H. R., Banadaky, M. D., \& Mesgaran, M. B. (2016) Variation in weed seed fate fed to different holstein cattle groups. PLoS One, 11, 1-15.

Saric-Krsmanovic, M., Bozic, D., Radivojevic, L., Gajic Umiljendic, J., \& Vrbnicanin, S. (2018) Response of alfalfa and sugar beet to field dodder (Cuscuta campestris Yunck.) parasitism: a physiological and anatomical approach. Canadian Journal of Plant Science, 99, 199-209.

Shaheen, H., Qureshi, R., Iqbal, S., \& Qasem, M. F. (2014) Seasonal availability and palatability of native flora of Santh Saroola Kotli Sattian, Rawalpindi, Pakistan. African Journal of Plant Science, 8, 92-102.

Shipley, L. A. (1999). Grasers and browsers: how digestive morphology affect diet selection. In K. L. Launchbaugh, K. D. Sanders, \& J. C. Mosley (Eds.), Proceedings 1999 Grazing behavior of livestock and wildlife. (University of Idaho, Moscow), pp. 20-27. University of Idaho, Moscow, Russia.

Taylorson, R. B., \& Hendricks, S. B. (1972) Phytochrome control of germination of Rumex crispus L. seeds induced by temperature shifts. Plant Physiology, 50, 645-648.

Tjelele, J. T., Dziba, L. E., \& Pule, H. T. (2012) Recovery and germination of Dichrostachys cinerea seeds fed to goats (Capra hircus). Rangeland Ecology and Management, 65, 105-108.

Traveset, A., Rodríguez-Pérez, J., \& Pías, B. (2008) Seed trait changes in dispersers' guts and consequences for germination and seedling growth. Ecology, 89, 95-106.

Traveset, A., \& Verdu, M. (2002) A meta-analysis of the effect of gut treatment on seed germination. In: Levey, D. J., Silva, W. R. and Galetti, M. (Eds.) Seed dispersal and frugivory: ecology, evolution and conservation. CABI International, Wallingford, pp. 339-350.

Tsiplakou, E., Hadjigeorgiou, I., Sotirakoglou, K., \& Zervas, G. (2011) Differences in mean retention time of sheep and goats under controlled feeding practices. Small Ruminant Research, 95, 48-53.

Wang, S., Lu, W., Waly, N., \& Ma, C. (2017) Recovery and germination of seeds after passage through the gut of Kazakh sheep on the north slope of the Tianshan Mountains. Seed Science Research, 27, 43-49.

Weaver, S. E., \& Riley, W. R. (1982) The biology of Canadian weeds: 53. Convolvulus arvensis L. Canadian Journal of Plant Science, 62, 461-472.

Welch, D. (1985) Studies in the grazing of heather moorland in north-east Scotland. IV. Seed dispersal and plant establishment in dung. Journal of Applied Ecology, 22, 461-472.

Yakhchali, M., \& Ranjbargarmabolia, B. (2008) Ixodid ticks fauna in sheep and goats flocks in Torbatejam suburb (South Khorasan province). Iran. Pajouhesh-va-sazandegi, 3, 27-32.

Zar, J. H. (2014) Biostatistical analysis, 5th ed. Pearson New International Edition. 